\title{
Long lasting time outdoor atmospheric corrosion tests: electrochemical analysis
}

\author{
M. Leiro ${ }^{1} \&$ E. S. Ayllón ${ }^{2}$ \\ ${ }^{I}$ Department of Corrosion Science, (Departamento Investigaciones en \\ Corrosión) CITEFA, Buenos Aires, Argentina \\ ${ }^{2}$ Department of Material Science and Technique, (Departamento \\ Ciencia y Técnica de Materiales) CITEFA, Buenos Aires, Argentina
}

\begin{abstract}
When submerging a pure metal or an alloy in an aqueous solution, a migration of metallic ions between the solid phase and the aqueous phase starts immediately. In fact, it is a constant exchange of metallic ions in which the prevailing speed will be the one leading to a decrease of the free energy $(\Delta \mathrm{W})$ of the system.

The passing of the metallic ions to the solution will create a potential difference in the metal-solution interface, which will hinder the passage of new ions. A potential difference will be reached, in which the free energy variation will be null, and a thermodynamic equilibrium will exist.

If the metal is submerged into a solution that has its own ions, the electrochemical potential will be different in each metal. Noble metals are those like gold $(\mathrm{Au})$, and Platinum $(\mathrm{Pt})$, whose ions are deposited on the metallic solid phase thus increasing their potential with respect to the solution. The metal will be traditionally more positive than the solution.

Those metals like Iron $(\mathrm{Fe})$ and Zinc $(\mathrm{Zn})$ will have a tendency to pass to a solution, no matter their ionic concentration, getting the metallic solid phase lower potentials than the solution, or negative potentials in contrast with noble metals.

The direct measurement of the potential difference between the metal and the solution is experimentally impossible. However, a cell with two electrodes can be formed to measure the potential difference between the two. One of the electrodes will be the pure metal or alloy, whose potential we are interested in finding out, and the other will be an electrode with an easy-to-reproduce potential to take it as a pattern.
\end{abstract}


The electrode taken as a reference is the one called hydrogen $(\mathrm{H})$ electrode, which is a platinised platinum electrode submerged in an acid solution $(\mathrm{pH}=0)$ with a hydrogen activity equal to $1.0 \mathrm{M}$, over which hydrogen bubbles at a specified atmospheric pressure. Traditionally, zero potential is assigned to every temperature.

Keywords: atmospheric corrosion, electrochemical analysis.

\section{Introduction}

Two different metallic electrodes together form a cell, for example, metallic $\mathrm{Cu}$ and $\mathrm{Zn}$ in solutions containing their own ions. The potential difference between these metals may be calculated from previous data. $\mathrm{Cu}$ will be $+0.34 \mathrm{~V}$ more positive than the solution, and $\mathrm{Zn}$ will be $-0.76 \mathrm{~V}$. The union through a salt bridge of both solutions leads to a potential measurement among electrodes of $1.1 \mathrm{~V}$. The measurement may be carried out through a very high impedance instrument.

If two electrodes are joined with an electron conductor - a copper wire, for instance-, we will get a current I circulation, which will be defined by the electrolyte resistance and the potential difference among the solutions adjacent to the electrodes. $\mathrm{Cu}^{++}$metallic ions will be deposited on the $\mathrm{Cu}$ electrode, and the $\mathrm{Zn}$ will dissolve thus $\mathrm{Zn}^{++}$ions forming part of the solution. This latter is an anodic reaction:

$$
\mathrm{Zn} \rightarrow \mathrm{Zn}^{++}+2 \mathrm{e}^{-}
$$

The $\mathrm{Cu}$ reaction is a cathodic one or a reaction in which electrons produced in the anodic reaction are consumed:

$$
\mathrm{Cu}^{++}+2 \mathrm{e}^{-} \rightarrow \mathrm{Cu}
$$

This is the electrochemical corrosion pattern or model. The $\mathrm{Zn}$ electrode corrodes itself and the $\mathrm{Cu}$ electrode gives the supplemented reaction. The electric current generated will be a measure of the reaction rate that will be the same in both electrodes unless other reactions appear.

The potential measured before the connection is a thermodynamic value informing about the possibility of a reaction, and the I current is a measure of the reaction kinetics.

If the electrodes potential with respect to the solutions in which they are submerged is measured when current circulates, we will observe that both of them varied from their initial stage. The $\mathrm{Cu}$ electrode will be less positive and the $\mathrm{Zn}$ one will be less negative. In order for the corrosion current to circulate, the electrodes have to leave their thermodynamic equilibrium; they have to polarise.

The difference between the new potential (E), which depends on the I current, and the initial one given by Nersnt equation, is called overpotential or overvoltage. 
The oxidation or anodic reaction produces electrons:

$$
\mathrm{Fe} \rightarrow \mathrm{Fe}^{2+}+2 \mathrm{e}^{-}
$$

The main cathodic or reducing reactions, which consume electrons is:

$$
\begin{gathered}
2 \mathrm{H}^{+}+2 \mathrm{e}^{-} \rightarrow \mathrm{H}_{2} \\
\mathrm{O}_{2}+4 \mathrm{H}^{+}+4 \mathrm{e}^{-} \rightarrow 2 \mathrm{H}_{2} \mathrm{O}
\end{gathered}
$$

These equations show the Fe electrochemical corrosion process. In general, the anodic reaction is the transfer of a metallic atom from the crystalline lattice to an aqueous solution like $\mathrm{Fe}^{+2}$ cation.

Likewise, the supplemented cathodic reaction is basically the consumption of electrons generated by different ways of anodic reactions with only one reducing equation or more. Here, the electron conduction is through the Fe mass generated by the Fe weight since it is a sample in which the anodic and cathodic areas are spontaneously produced. Both reactions may be studied individually through electrochemical techniques.

These apply a particular potential to the sample; they measure the current flow or control this flow and measure the resulting potential. These are called polarisation techniques. Diagrams of the E applied potential are obtained, and the potential is measured with respect to a reference electrode - in volts or milivolts, generally-, based on the Log I. I is the current density; the measured current divided by the tested sample area $\left(\mathrm{A} . \mathrm{cm}^{-2}\right)$.

The corrosion potential may be measured with a reference electrode by means of a high impedance instrument. In general, a calomel saturated reference electrode is commonly used in all electrochemical laboratories.

When it is necessary to express the values obtained in the hydrogen scale, these are transformed as follows:

$$
\text { Hydrogen scale }=\text { calomel saturated scale }+240 \mathrm{mV}
$$

A traditional Pyrex glass electrochemical cell - as it is shown in Figure 1 with a magnetic stirrer was used to keep the hydrodynamic conditions of the system constant. The cell - around $120 \mathrm{ml}$ - has six inputs. The main one, which coincides with the axis of axial revolution symmetry of the cell, is for the work electrode, made up of a sample of the material to be tested, and whose exposed surface is around $1 \mathrm{~cm}^{2}$. The remaining four superior inputs are used for the reference electrode, the platinum $(\mathrm{Pt})$ wire counterelectrode, and output and input gases tubes. Laterally, and at $45^{\circ}$ from the cell axis, there is another input for a glass electrode to measure the $\mathrm{pH}$ of the solution, which can be done continuously during the test.

The reference electrode used was a calomel saturated one. It had an agar/ $\mathrm{Na}_{2} \mathrm{SO}_{4} 0.1 \mathrm{M}$ salt bridge - through a capillary called Luggin with $\phi$ diameter in its end, and located at $\phi$ distance from the work electrode surface. The current 


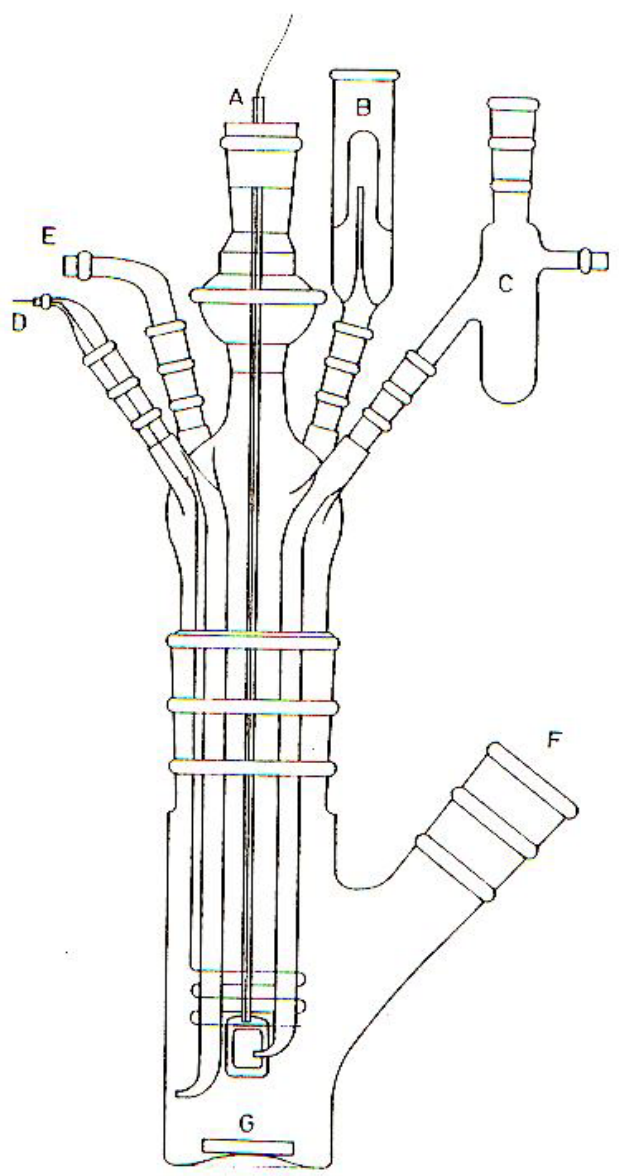

Figure 1: Traditional glass cell for electrochemical tests. A: Work electrode; B: Gases output with water trap; C: Reference electrode holder; D: Pt counterelectrode; E: Gases input; F: Input for complementary measurements of $\mathrm{T}, \mathrm{pH},\left[\mathrm{M}^{+\mathrm{n}}\right]$, etc.; G: Submerged device to magnetically stir the solution.

density in the counterelectrode surface must be low in order not to exceed the potentiostat capacity. Therefore, its area must exceed the one of the sample in at least 10 (ten) times. The work electrode was prepared by setting the sample in a glass tube end with epoxy resin, which was also used to protect the edges and back. A $\mathrm{Cu}$ wire with a diameter of $1 \mathrm{~mm}$ was used inside the glass tube to connect it with the cell outer circuit.

The curves were drawn with a Tacussel PRT-20-2X Potentiostat with a Servovit 13 scanning generator. This equipment keeps constant the specimen E potential with respect to the reference electrode. The resultant cathodic $\left(I_{c}\right)$ or 
anodic $\left(\mathrm{I}_{\mathrm{a}}\right)$ current - which can be measured in the cell outer circuit- closes with ions by means of the pt counterelectrode. The E potential may be constant or may vary, according to a preset law. Here, a variation linear law with a $10 \mathrm{mV} \cdot \mathrm{min}^{-1}$ slope was adopted. The curves started from the equilibrium potential - were the overpotential and the current are null- scanning in anodic or cathodic direction up to $+1200 \mathrm{mV}$ and $-1300 \mathrm{mV}$, respectively. The curves were drawn in triplicate at environmental temperature, showing their anodic and cathodic averages.

The $I_{\text {corr }}\left(\mathrm{A}_{\mathrm{c}} \mathrm{cm}^{-2}\right)$ corrosion current was determined as the intersection of the cathodic curve slope in the Tafel zone and the rest potential horizontal - also called open circuit since no current flows-coincides with the $\mathrm{E}_{\mathrm{c}}$ corrosion potential, and reveals a value of $5 \cdot 10^{-6} \mathrm{~A} \cdot \mathrm{cm}^{-2}$. The cathodic curve does not change sensitively if drawn in the same stirred solution and if it is oxygensaturated by air bubbling, which shows that oxygen reduction does not interfere and that there are other cathodic reactions involved. The passivation current value of the patina reveals its protective attribute. Polished steel up to $0.25 \mu \mathrm{m}$ shows a constant increase of the current with the applied overpotential increase. The specimens exposed at Villa Martelli outdoor tests station for 1-9 years reveal that Cor Ten A steel increases continuously its passive nature [2].

The protective attribute of corrosion products on steels depends on the climatic conditions of the place where they are formed. This was shown by the electrochemical test described: low carbon steel without microalloying elements in different test stations in Ibero-American countries, as shown in fig. 2 [3].

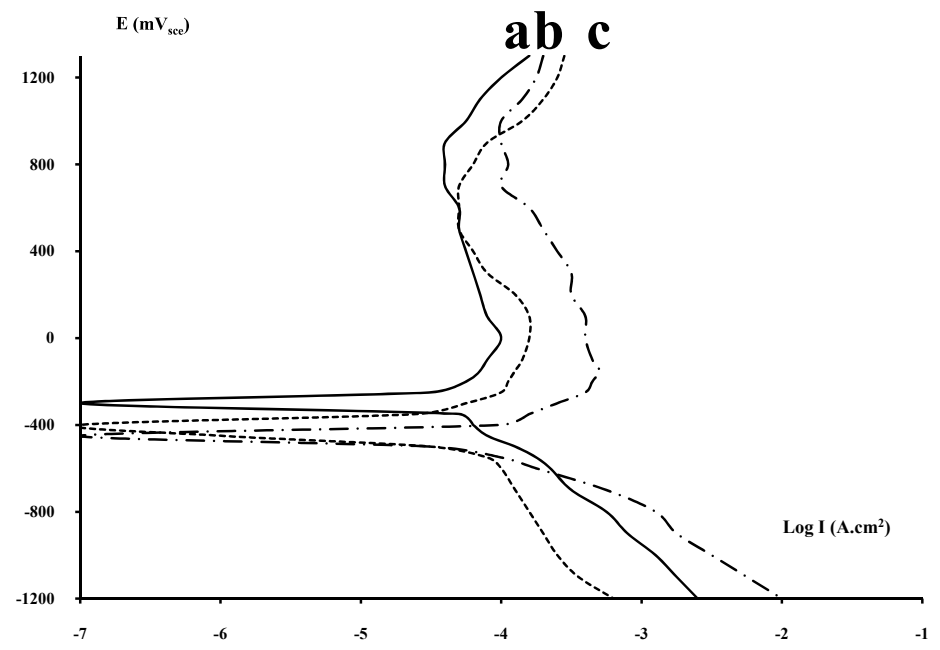

Figure 2: Polarisation curves of low carbon steel in $\mathrm{Na}_{2} \mathrm{SO}_{4} 0.1 \mathrm{M}$ at $25^{\circ} \mathrm{C}$, exposed at 3 outdoor tests stations for 1 year. 


\section{Electrochemical analysis: non-metallic inclusions reactivity test}

Cor Ten A and PA steel specimens polished with diamond paste up to $0.25 \mu \mathrm{m}$ were polarised anodically to determine the pitting potential (Ep) of these steels in a buffered solution at $\mathrm{pH}=9$ with $\mathrm{NaCl} 0.05 \mathrm{M}$.

The test was carried out in triplicate using specimens of $1 \mathrm{~cm}^{2}$ of the area exposed to the electrolyte; and it was polarised at a scanning rate of $10 \mathrm{mV}$.min1 from the rest potential to the pitting potential, which was $\mathrm{Ep}=-180 \mathrm{mV}$ for both steels. The said potential remained constant and the corrosion attack was nucleated, recording time-based currents. In Figure 3, the Curve Log $I=f(t)$ can be observed, showing the nucleation kinetics of the PA steel attack in contrast with Cor Ten A.

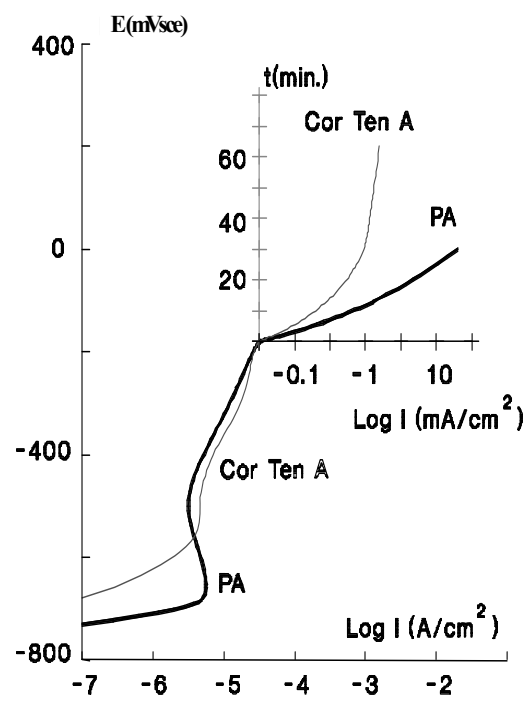

Figure 3: Reactivity inclusions test on PA and Cor Ten A steels, polished up to $0.25 \mu \mathrm{m}$.

\subsection{Polarisation curves}

Anodic and cathodic polarisations were performed on PA steel samples exposed for 6 years to the open air in VILLA MARTELLI; the results are shown in Figure 4. The same experimental technique described in I4I, for a Cor Ten A steel exposed for 15 years in the same station was used. This curve has been reproduced for the sake of comparison. The corrosion current $\left(i_{c}\right)$ and Tafel slopes were calculated by the GAMMACRUNCH [4] programme, which was used by its authors for different corrosion problems $[5,6]$. The results were as follows: $\mathrm{i}_{\mathrm{c}}=210^{-7} \mathrm{~A} / \mathrm{cm}^{2} ; \mathrm{b}_{\mathrm{c}}=-201.8 \mathrm{mV} /$ dec.; $\mathrm{b}_{\mathrm{a}}=218.8 \mathrm{mV} / \mathrm{dec}$. 


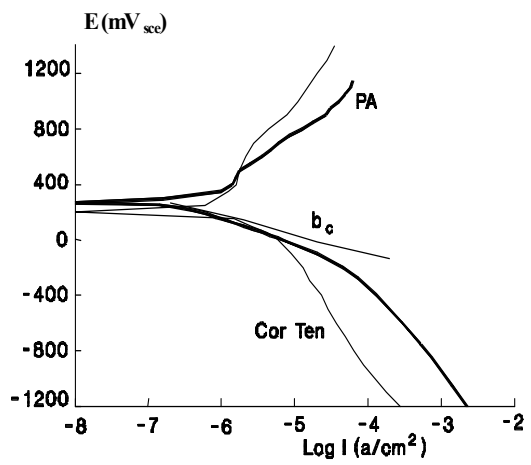

Figure 4: $\quad$ Polarisation curves in $\mathrm{Na}_{2} \mathrm{SO}_{4} 0.1 \mathrm{M}$ of PA steel exposed for 6 years; and of Cor Ten A steel exposed for 15 years in VILLA MARTELLI urban site.

This result was compared with the results of weight loss, previously obtained by outdoor exposure.

$$
\Delta W=\frac{i_{\mathcal{C}} \text {.eqivg. }}{2 . F}=0.05 \mathrm{~g} / \mathrm{m}^{2} \text { day }
$$

The value obtained is a 6-year exposure average: $\Delta \mathrm{W} \approx 0.072 \mathrm{~g} / \mathrm{m}^{2}$ per day, resulting from the same order.

The results obtained by the GAMMACRUNCH programme allow the calculation of the polarisation resistance. [4].

$$
\frac{\Delta E}{\Delta I}=2.303 * i_{\text {corr }} * \frac{b a+[b c]}{b a *[b c]}=4.10^{-9} \mathrm{~A} / \mathrm{mV} . . \mathrm{cm}^{2}
$$

Considering $\Delta \mathrm{E}=20 \mathrm{mV}$, and $\Delta \mathrm{i}=0.08 \mu \mathrm{A} / \mathrm{cm}^{2}$

The experimentally obtained value for $\Delta \mathrm{E}=20 \mathrm{mV}_{\text {sce }}$ was $0.024 \pm$ $0.014 \mu \mathrm{A} / \mathrm{cm}^{2}$, resulting from the same order, which was previously calculated.

\subsection{Cyclic polarisation curves}

They were performed from the rest potential or the Er open circuit at a scanning rate of $100 \mathrm{mV} \cdot \mathrm{min}^{-1}$ in anodic direction up to $+1300 \mathrm{mV}$ in order to start from there an anodic-cathodic cycle up to $-1200 \mathrm{mV}$, and back again at $+1300 \mathrm{mV}$. Results for PA steel, Cor Ten A steel and SAE 1020 steel (C: 0.2; Mn: 0.5; P: 0.01; S: 0.024; $\mathrm{Si}: 0.09$ ), exposed simultaneously with PA steel, are shown in Figure $5 \mathrm{a}), \mathrm{b})$, and c), respectively. 

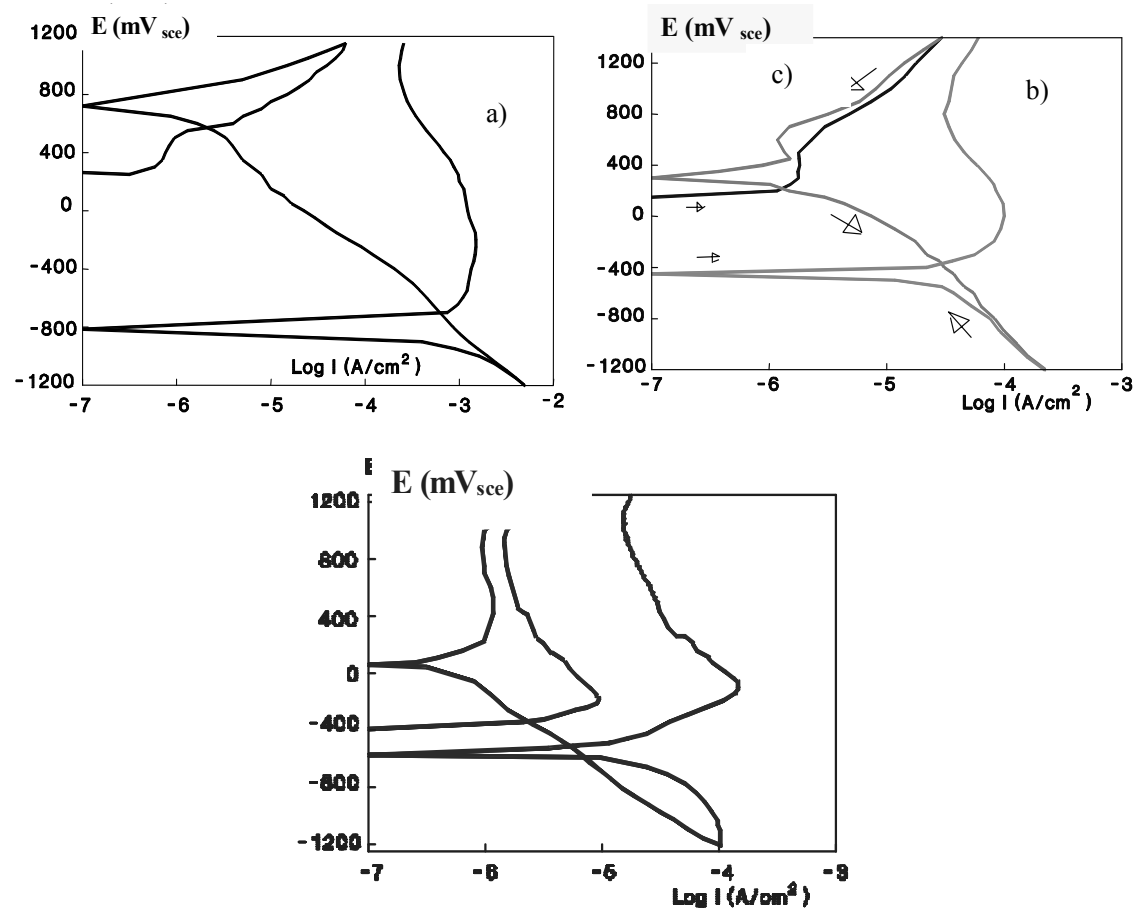

Figure 5: $\quad$ Steel cyclic polarisation curves; a) PA steel exposed for 6 years; b) Cor Ten A steel exposed for 15 years; c) SAE 1020 steel exposed simultaneously with the PA steel in the urban site of VILLA MARTELLI outdoor test station.

\subsection{Test on corrosion products film reduction}

These tests were carried out at a potential scanning rate of $2.77 \mathrm{mV} . \mathrm{min}^{-1}$, from the rest potential and in a cathodic direction. The electrolyte used was a $\mathrm{Na}_{2} \mathrm{SO}_{4}$ $0.1 \mathrm{M}$ solution at $25^{\circ} \mathrm{C}$ with an initial $\mathrm{pH}=6.3$, and a rotation rate of the magnetic stirrer of $60 \mathrm{rpm}$, which remained constant in all the tests performed. The $\mathrm{pH}$ of the solution was measured all the time by an electrode and a Tacussel Minises 8000 electron equipment. The scanning was performed up to $-950 \mathrm{mV}$, and samples of the solution were taken, the $\mathrm{Fe}^{+2}$ content of which was analysed in a Carl Zeiss M4QIII atomic absorption equipment.

Following the cathodic treatment, the specimen potential was stabilised, and an anodic scanning at $100 \mathrm{mV} \cdot \mathrm{min}^{-1}$ was performed from the said potential up to $+700 \mathrm{mV}$. The results of a non-weathering SAE 1020 steel, and a PA weathering steel after six years' exposure in the urban site of VILLA MARTELLI outdoor test station are shown in Figure 5, Table 1. Both steels were exposed simultaneously to the same site. 
Table 1: $\quad \mathrm{pH}$ and $\left(\mathrm{Fe}^{+2}\right)_{\text {aq. }}$ based on the PA steel potential in the cathodic reduction test.

\begin{tabular}{|c|c|c|c|c|c|}
\hline Potential (mVsce) & $\mathbf{+ 2 0 0}$ & $\mathbf{- 2 0 0}$ & $\mathbf{- 7 0 0}$ & $\mathbf{- 9 0 0}$ & $\mathbf{- 1 1 0 0}$ \\
\hline $\mathbf{P H}$ & 6.3 & 7.3 & 5.3 & 5.2 & 6.3 \\
\hline$\left(\mathbf{F e}^{+\mathbf{2}}\right)_{\text {aq. }}$ (ppm) & ---- & ----- & $=1$ & $=1$ & 11.7 \\
\hline
\end{tabular}

The measurement of the areas under the anodic and cathodic curves (Figure 6) is proportional to the $\mathrm{Q}$ charge, which has flowed during the anodic and cathodic processes. The E potential axis $\left(\mathrm{mV}_{\text {sce }}\right)$ may be considered as time (in seconds), since the scanning rate is constant during the test.

$$
\mathrm{Q}=\mathrm{a} . \int \mathrm{Idt}=\mathrm{a}^{\cdot} \int \mathrm{IdV} \quad[1]
$$

The PA steel values measured by the Simpson formula show that the cathodic area is bigger than the anodic one in the $\mathrm{z}=1.63$ ratio.

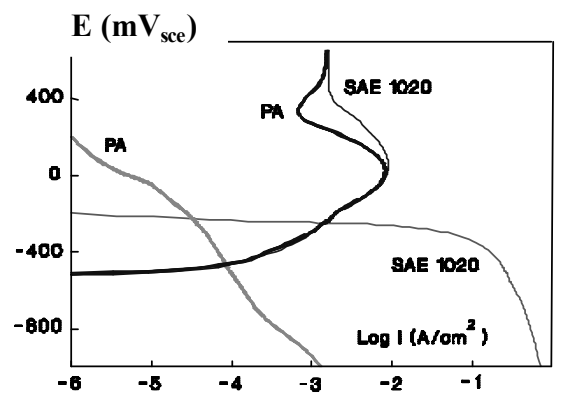

Figure 6: Cathodic reduction curves of corrosion products formed in the open air, and anodic curves on the same sample after the cathodic test.

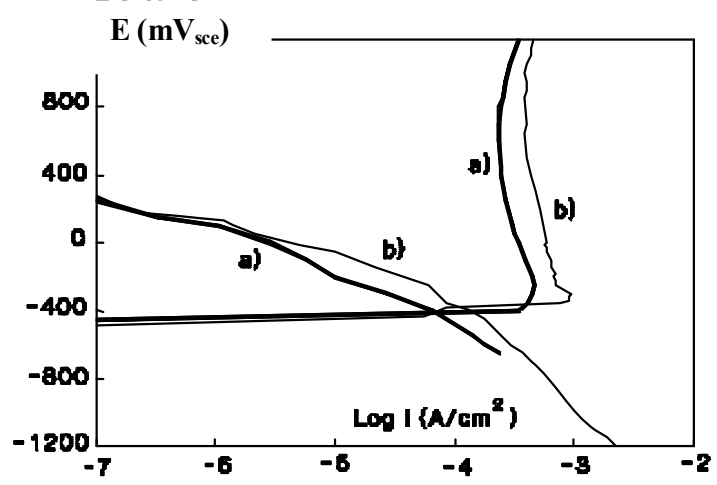

Figure 7: Curves a) Cathodic reduction at $2.77 \mathrm{mV} / \mathrm{min}$, and following anodic reduction at $100 \mathrm{mV} / \mathrm{min}$; Curves b) Cathodic reduction at $100 \mathrm{mV} / \mathrm{min}$., and following anodic curve at the same rate. 
The curves in Figure 7 show the results of a cathodic reduction at two different scanning rates: Curves a) cathodic reduction at $2.77 \mathrm{mV} / \mathrm{min}$. up to a potential of $-650 \mathrm{mV}_{\text {sce. }}$ b) at $100 \mathrm{mV} / \mathrm{min}$ up to $-1200 \mathrm{mVsce}$. The following anodic curve at $100 \mathrm{mV} / \mathrm{min}$. shows a maximum current to the $\mathrm{E}$ potential $=-235$ $\mathrm{mVsce}$, and $\mathrm{E}=-300 \mathrm{mVsce}$, respectively.

Figure 8 summarises the characteristics of the three cathodic reductions of the PA steel, and the anodic and cathodic loads, respectively.

Left column:

Cathodic load.

Right column:

Anodic load.

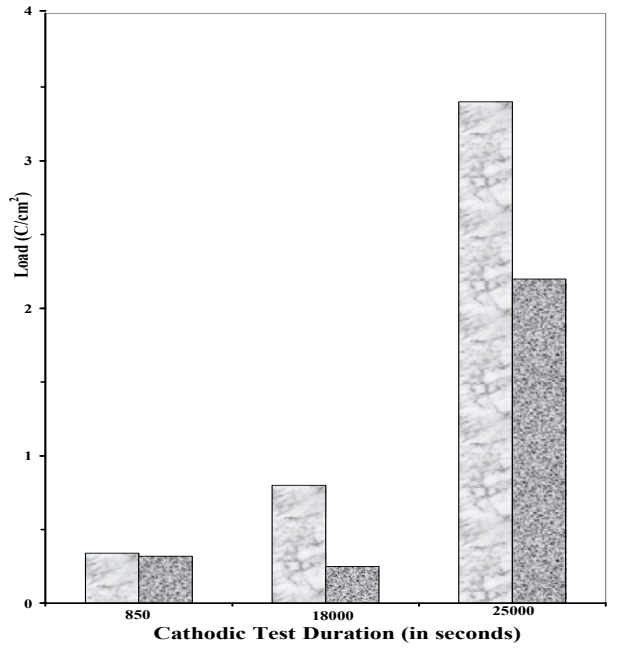

\begin{tabular}{|c|c|c|c|}
\hline Cathodic test duration (in seconds) & 850 & 18000 & 25000 \\
\hline Curve of & Curve b & Curve a & PA Curve \\
\hline Cathodic scanning rate $(\mathrm{mV} / \mathrm{min})$. & 100 & 2.77 & 2.77 \\
\hline Cathodic potential achieved $\left(\mathrm{mV}_{\text {sce }}\right)$ & -1200 & -650 & -950 \\
\hline Maximum anodic current in $\mathrm{E}=\left(\mathrm{mV}_{\text {sce }}\right)$ & -300 & -235 & -40 \\
\hline Load balance (cathodic/anodic) & 1.1 & 4.1 & 1.63 \\
\hline
\end{tabular}

Figure 8: Summary of the characteristics of the cathodic reduction curves, and cathodic and anodic loads, exchanged among the PA steel corrosion products and the electrolyte.

These results were supplemented with the measurement of the Ec corrosion potential evolution of the PA steel, considering de immersion time in a $\mathrm{Na}_{2} \mathrm{SO}_{4}$ $0.1 \mathrm{M}$ solution (Figure 5). Curve a) was drawn at a $\mathrm{pH}=6.0$, which remained constant during the 900 hours of the test. On the other hand, Curve b) corresponds to a test similar to the previous one, which showed a $\mathrm{pH}=4.0$ at first, and that varied until achieving a 5.6 value after 100 hours. In Curve c), a $\mathrm{pH}=4.0$ buffer was used; the potential decreased quicker at first, but then it stabilised at the same potential values. During this last test, no corrosion product precipitation was observed in the solution; and the test was stopped when the full loosening of the patina outer layer - without being fragmentised - occurred. 


\section{Conclusion}

The results from electrochemical tests, particularly those about cathodic reactions of patina formed in the open air, show the way the different factors influence on magnectite formation as a final product of the said reactions. These experimental results allow to explain the way the PA steel cathodic curve shows three current orders, which are inferior to the non-weathering reference ones until achieving reduction potentials from the inner layer compounds to magnetite, thus having the weathering steel corrosion product film a protective attribute similar to the one presented by non-weathering steels.

Therefore, it is inferred that the controlling mechanism of the patina protective attribute results from the compactness provided by the microalloying elements, which leads to a decrease of the pores and particles size.

\section{References}

[1] J.R. Galvele, Corrosion, CNEA-OEA, p. 17, (1979).

[2] B. M. Rosales and E.S. Ayllon, Atmospheric Corrosion, 27,28,35, J.W. \& Sons. Inc., (1982).

[3] S. L. Granese, E. S. Ayllon, B.M. Rosales, F. E, Varela, C.A, Gervasi and J. R. Vilche, Proc. First Pan-American Corrosion and Protection Congress, Mar del Plata, Argentina, 1, p. 200, (1992)

[4] D. Britz, Programa GAMMACRUNCH (GRAMMACRUNCH Program), Private Communication, April 1994.

[5] M. Jensen and D. Britz, Corrosion 46, N 2, p. 111, (1990).

[6] M. Jensen and D. Britz, Corrosion Sci, 32, N 3, p. 285 (1991) 